\title{
A comparative analysis of the effects of sevoflurane and propofol on cerebral oxygenation during steep Trendelenburg position and pneumoperitoneum for robotic-assisted laparoscopic prostatectomy
}

\author{
Aya Doe $^{1} \cdot$ Motoi Kumagai $^{1}$ (I) $\cdot$ Yuichiro Tamura $^{1} \cdot$ Akira Sakai $^{1} \cdot$ Kenji Suzuki $^{1}$
}

Received: 14 April 2016 / Accepted: 13 August 2016 / Published online: 26 August 2016

(C) The Author(s) 2016. This article is published with open access at Springerlink.com

\begin{abstract}
Purpose Steep Trendelenburg position and pneumoperitoneum during robotic-assisted laparoscopic prostatectomy (RALP) increase intracranial pressure (ICP) and may alter cerebral blood flow (CBF) and oxygenation. Volatile anesthetics and propofol have different effects on ICP, CBF, and cerebral metabolic rate and may have different impact on cerebral oxygenation during RALP. In this study, we measured jugular venous bulb oxygenation $\left(\mathrm{SjO}_{2}\right)$ and regional oxygen saturation $\left(\mathrm{SctO}_{2}\right)$ in patients undergoing RALP to evaluate cerebral oxygenation and compared the effects of sevoflurane and propofol. We also verified whether $\mathrm{SctO}_{2}$ may be an alternative to $\mathrm{SjO}_{2}$.

Methods Fifty patients scheduled for RALP were randomly assigned to undergo sevoflurane (group $\mathrm{S}$ ) or propofol (group P) anesthesia. $\mathrm{SjO}_{2}$, $\mathrm{SctO}_{2}$, mean arterial pressure (MAP), heart rate (HR), cardiac index (CI), central venous pressure (CVP), partial pressures of arterial oxygen $\left(\mathrm{PaO}_{2}\right)$ and carbon dioxide $\left(\mathrm{PaCO}_{2}\right)$, hemoglobin concentration $(\mathrm{Hb})$, Bispectral Index (BIS) and nasopharyngeal temperature (BT) were recorded $5 \mathrm{~min}$ before surgery commencement, $5 \mathrm{~min}$ after pneumoperitoneum, 5, 30, 60, 90, and 120 min after pneumoperitoneum in a Trendelenburg position, and after desufflation in a supine position.

Results $\mathrm{SjO}_{2}$ was significantly higher in group $\mathrm{S}$ than in group $\mathrm{P}$ at all measurement points [group $\mathrm{S}$ vs. group $\mathrm{P}$ : $77 \%$ (11) vs. $65 \%$ (13), mean of all measurement points (1SD); $p<0.01]$. Linear regression analysis $(\beta=0.106$;
\end{abstract}

Motoi Kumagai

bear@kxd.biglobe.ne.jp

1 Department of Anesthesiology, School of Medicine, Iwate Medical University, 19-1 Uchimaru, Morioka 020-0023, Japan $\left.r^{2}=0.065 ; p=0.004\right)$ shows a weak relationship between $\mathrm{SjO}_{2}$ and $\mathrm{SctO}_{2}$.

Conclusions Sevoflurane maintains higher $\mathrm{SjO}_{2}$ levels than propofol during RALP. $\mathrm{SctO}_{2}$ does not accurately reflect $\mathrm{SjO}_{2}$.

Keywords Robotic-assisted laparoscopic prostatectomy (RALP) · Steep Trendelenburg position · Cerebral oxygenation $\cdot$ Sevoflurane $\cdot$ Propofol

\section{Introduction}

Robotic-assisted laparoscopic prostatectomy (RALP) requires a steep Trendelenburg position and pneumoperitoneum, both of which can increase intracranial pressure (ICP) $[1,2]$. Increased ICP, in turn, may decrease cerebral perfusion pressure and cerebral oxygenation [3, 4].

Although sevoflurane and propofol are commonly used anesthetics, they have different effects on cerebral blood flow (CBF) and the cerebral metabolic rate for oxygen $\left(\mathrm{CMRO}_{2}\right)$. Volatile anesthetics primarily increase $\mathrm{CBF}$ via local vasodilatation and reduce $\mathrm{CMRO}_{2}$. At low concentrations, where the effect of $\mathrm{CMRO}_{2}$ is dominant, these anesthetics constrict cerebral vessels by suppressing $\mathrm{CMRO}_{2}$ and prevent an increase in the $\mathrm{CBF}$ and $\mathrm{CBF} / \mathrm{CMRO}{ }_{2}$ ratio. At the medium-to-high concentrations commonly used in clinical settings, the direct vasodilatory effect becomes dominant, causing $\mathrm{CBF}$ and the $\mathrm{CBF} / \mathrm{CMRO}_{2}$ ratio to increase. With sevoflurane, this effect is accompanied by an increase in cerebral blood volume (CBV) and an elevated ICP [5]. In RALP, where ICP is already increased, it is conceivable that the $\mathrm{CBV}$ increase caused by volatile anesthetics could further increase ICP and in turn lower the $\mathrm{CBF}$ / $\mathrm{CMRO}_{2}$ ratio and cerebral oxygenation. Supporting this 
hypothesis, one study showed cerebral oxygen desaturation in a steep Trendelenburg position and pneumoperitoneum with isoflurane anesthesia [4]. Propofol reduces CBF by cerebral vasoconstriction and suppresses $\mathrm{CMRO}_{2}$. The relationship between the vasoconstriction and $\mathrm{CMRO}_{2}$ suppression effects of propofol is unclear; some studies have reported approximate equivalency [6], and others have reported that vasoconstriction is slightly dominant [7]. Propofol at least does not increase the $\mathrm{CBF} / \mathrm{CMRO}_{2}$ ratio. Volatile anesthetics and propofol each have the potential to decrease cerebral oxygenation during RALP.

Patients undergoing RALP are typically elderly and often have cerebrovascular disease that is associated with impaired cerebral oxygenation. These are not only associated with cerebral vasoconstriction or vasospasm during surgery but also with postoperative cognitive decline (POCD) [8]. Some studies suggest that the choice of anesthetic affects cerebral oxygenation and POCD [9, 10]. Thus, it is important to monitor cerebral oxygenation and choose anesthetics that best preserve cerebral oxygenation.

Jugular venous bulb oxygen saturation $\left(\mathrm{SjO}_{2}\right)$ accurately reflects the $\mathrm{CBF} / \mathrm{CMRO}_{2}$ ratio but is invasive and complex [11]. By contrast, near-infrared spectroscopy (NIRS) can non-invasively assess $\mathrm{SctO}_{2}$, which can reflect the $\mathrm{CBF} /$ $\mathrm{CMRO}_{2}$ ratio [12]. However, it has also been suggested that $\mathrm{SctO}_{2}$ and $\mathrm{SjO}_{2}$ are poorly correlated $[12,13]$.

To date, the difference in $\mathrm{SjO}_{2}$ between common anesthetic agents has not been investigated during RALP. In this study, we compared the effects of sevoflurane and propofol on $\mathrm{SjO}_{2}$, and verified whether $\mathrm{SctO}_{2}$ could be used as an alternative to $\mathrm{SjO}_{2}$ during RALP.

\section{Methods}

The institutional ethics committee of Iwate Medical University Hospital, Japan, approved this study, and it has been registered in the UMIN Clinical Trials Registry (UMIN000016685). After obtaining written informed consent, we enrolled adult male patients who were undergoing RALP with the requirement that they were American Society of Anesthesiologists physical status class 1 or 2 . Patients with known histories of cerebral ischemia or hemorrhage were excluded. Participants were randomized by computer generation into groups that received either sevoflurane (group S) or propofol (group P).

Anesthesia was induced in group $\mathrm{S}$ by a bolus injection of thiopental $(5 \mathrm{mg} / \mathrm{kg})$ and in group P by an effectsite target-controlled infusion (TCI) of propofol of $5 \mu \mathrm{g} /$ $\mathrm{ml}$; remifentanil $(0.2-0.4 \mu \mathrm{g} / \mathrm{kg} / \mathrm{min})$ was used in both groups. After administering rocuronium $(0.8 \mathrm{mg} / \mathrm{kg})$, the trachea was intubated and the lungs were mechanically ventilated in volume control mode (tidal volume $8-10 \mathrm{ml} /$ $\mathrm{kg}$ ) with an oxygen fraction $\left(\mathrm{FiO}_{2}\right)$ of 0.45 . The respiratory rate was adjusted to maintain an end-tidal carbon dioxide tension $\left(\mathrm{ETCO}_{2}\right)$ of $35-40 \mathrm{mmHg}$. In both groups, the concentrations of sedative drugs were adjusted to achieve a Bispectral Index (BIS) of 40-60. Sevoflurane was initiated at concentrations of $2.0 \%$ and adjusted above $1.7 \%$ (one minimum alveolar concentration; MAC), and propofol was maintained by TCI. Also, remifentanil was adjusted to maintain a mean arterial pressure (MAP) within $20 \%$ of the preinduction value in both groups. When the MAP decreased to $80 \%$ of the preinduction value, it was treated with an 8-mg bolus of ephedrine. Patients not anesthetized under these conditions were excluded from the final analysis.

Routine monitoring including electrocardiography, pulse oximetry, and non-invasive automated blood pressure measurement, started on arrival in the operating room. After the induction of anesthesia, a radial artery catheter was inserted for direct arterial blood pressure measurement and blood sampling. The arterial line was also connected to a FloTrac sensor and a third-generation Vigileo monitoring system (Edwards Lifesciences, Irvine, CA, USA) to monitor the cardiac index (CI) data. The $\mathrm{ETCO}_{2}$ and endtidal concentration of sevoflurane were measured using a Vamos anesthetic gas monitor (Dräger Japan, Tokyo, Japan). Central venous pressure (CVP) was measured by a single-lumen central venous catheter that was inserted into the right internal jugular vein. A BIS electrode was applied to the forehead and was measured continuously using an Aspect BIS A2000 monitor v3.31 (Aspect Medical Systems, Natick, MA, USA). Nasopharyngeal temperature (BT) was monitored continuously.

For $\mathrm{SctO}_{2}$ measurement, the cerebral oximeter probes were placed bilaterally $\geq 1 \mathrm{~cm}$ above each eyebrow. $\mathrm{SctO}_{2}$ was monitored with an INVOS5100B cerebral oximeter (Somanetics, Troy, MI, USA), and the values from each side were averaged. For the continuous monitoring of $\mathrm{SjO}_{2}$, a Pre-Sep Oximetry Catheter (Edwards Lifesciences, Irvine, CA, USA) was connected to the Vigileo system and placed in the left jugular venous bulb. The catheter position was verified radiographically.

We recorded the $\mathrm{SjO}_{2}, \mathrm{SctO}_{2}$, MAP, heart rate (HR), CI, CVP, $\mathrm{PaO}_{2}, \mathrm{PaCO}_{2}$, hemoglobin concentration (Hb), BIS, and $\mathrm{BT}$ at the following points: $5 \mathrm{~min}$ before surgery (T0); $5 \mathrm{~min}$ after inducing a $15 \mathrm{mmHg}$ pneumoperitoneum (T1); $5,30,60,90$, and 120 min after inducing the pneumoperitoneum in a $30^{\circ}$ Trendelenburg position (T2, T3, T4, T5, and $\mathrm{T} 6$, respectively); and after desufflation in a supine position (T7).

Based on a pilot study, the sample size was calculated to detect a $9 \%$ difference in the mean $\mathrm{SjO}_{2}$ value at $\mathrm{T} 7$ using G power: $68 \%( \pm 9 \%)$ for group P compared with $77 \%( \pm 11 \%)$ for group $\mathrm{S}$. The power analysis indicated 
Table 1 Demographic and anesthetic data

\begin{tabular}{lccc}
\hline & Group S $(n=22)$ & Group P $(n=19)$ & $p$ value \\
\hline Age (years) & $67(4)$ & $66(4)$ & 0.21 \\
Weight (kg) & $67(8)$ & $68(6)$ & 0.65 \\
Height (cm) & $165(6)$ & $166(5)$ & 0.22 \\
Anesthetic time (min) & $284(39)$ & $282(37)$ & 0.69 \\
Operation time (min) & $201(40)$ & $201(32)$ & 0.73 \\
Fluid administered (ml) & $1132(362)$ & $1103(287)$ & 0.78 \\
Blood loss (ml) & $94(119)$ & $108(81)$ & 0.65 \\
Urine output (ml) & $163(124)$ & $121(82)$ & 0.15 \\
Ephedrine administered (mg) & $47(20)$ & $40(16)$ & 0.11 \\
Total dose of remifentanil administered (mg) & $4.2(1.2)$ & $4.7(0.8)$ & 0.19 \\
\hline
\end{tabular}

Data are presented as the mean (SD). There were no statistically significant differences between the two groups

that we needed a minimum sample size of 17 patients per group to detect an effect size of 0.89 using independent Student's $t$ tests with an $\alpha$ of 0.05 and a power of 0.80 . Thus, we aimed to include 25 patients per each group to allow for a $30 \%$ drop-out rate. The Shapiro-Wilk test was used to test the normality of the data. Demographic variables, duration of surgery and anesthesia, ephedrine and remifentanil doses, blood loss, urine output, and intravenous fluid volume between groups were compared using unpaired Student's $t$ tests. A two-way repeated-measures analysis of variance (ANOVA) with post hoc unpaired $t$ test and Bonferroni correction was used to compare $\mathrm{SjO}_{2}$, $\mathrm{SctO}_{2}, \mathrm{MAP}, \mathrm{HR}, \mathrm{CI}, \mathrm{CVP}, \mathrm{PaO}_{2}, \mathrm{PaCO}_{2}, \mathrm{Hb}, \mathrm{BT}$, and BIS between the groups. A one-way repeated-measures ANOVA with Bonferroni post hoc tests was used to analyze these variables across time within the groups. All statistical tests were two-tailed. The correlation between $\mathrm{SjO}_{2}$ and $\mathrm{SctO}_{2}$ was evaluated by simple linear regression. Significance was determined at $p<0.05$, and we used XLSTAT 2015 for Windows (Addinsoft, New York, USA) for all analyses. Data are expressed as mean (standard deviation).

\section{Results}

Of the 50 patients who were scheduled to enroll in the study, seven (three in group $\mathrm{S}$ and four in group $\mathrm{P}$ ) were excluded. One patient in group $\mathrm{P}$ was found to have a history of cerebral infarction after consenting to the study and six withdrew their consent before the operation. In group P, an additional two patients were excluded, one because nicardipine was administered to treat intraoperative hypertension, and another because the $\mathrm{FiO}_{2}$ needed to be increased beyond the protocol limit to maintain the $\mathrm{SaO}_{2}>94 \%$. All of the measured values were normally distributed. There were no major complications on normal postoperative

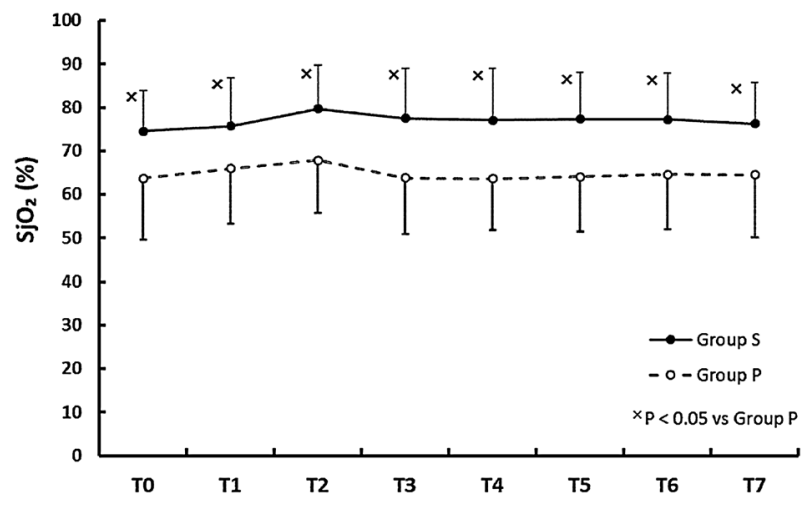

Fig. 1 The time courses of jugular venous oxygen saturations $\left(\mathrm{SjO}_{2}\right)$ in groups that received sevoflurane (filled circle) and propofol (opened circle). Values are expressed as mean (SD). Multi symbol $p<0.05$ vs. group $\mathrm{P}$

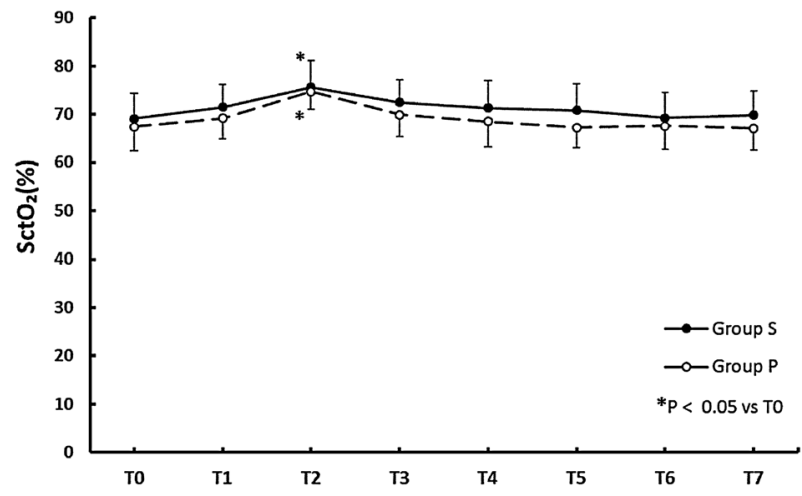

Fig. 2 The time courses for regional oxygen saturations $\left(\mathrm{SctO}_{2}\right)$ in groups receiving sevoflurane (filled circle) and propofol (opened circle). Values are expressed as mean (SD). $* p<0.05$ vs. T0

rounds in either group. As shown in Table 1, there were no significant differences in the demographic or anesthetic data between the groups. 

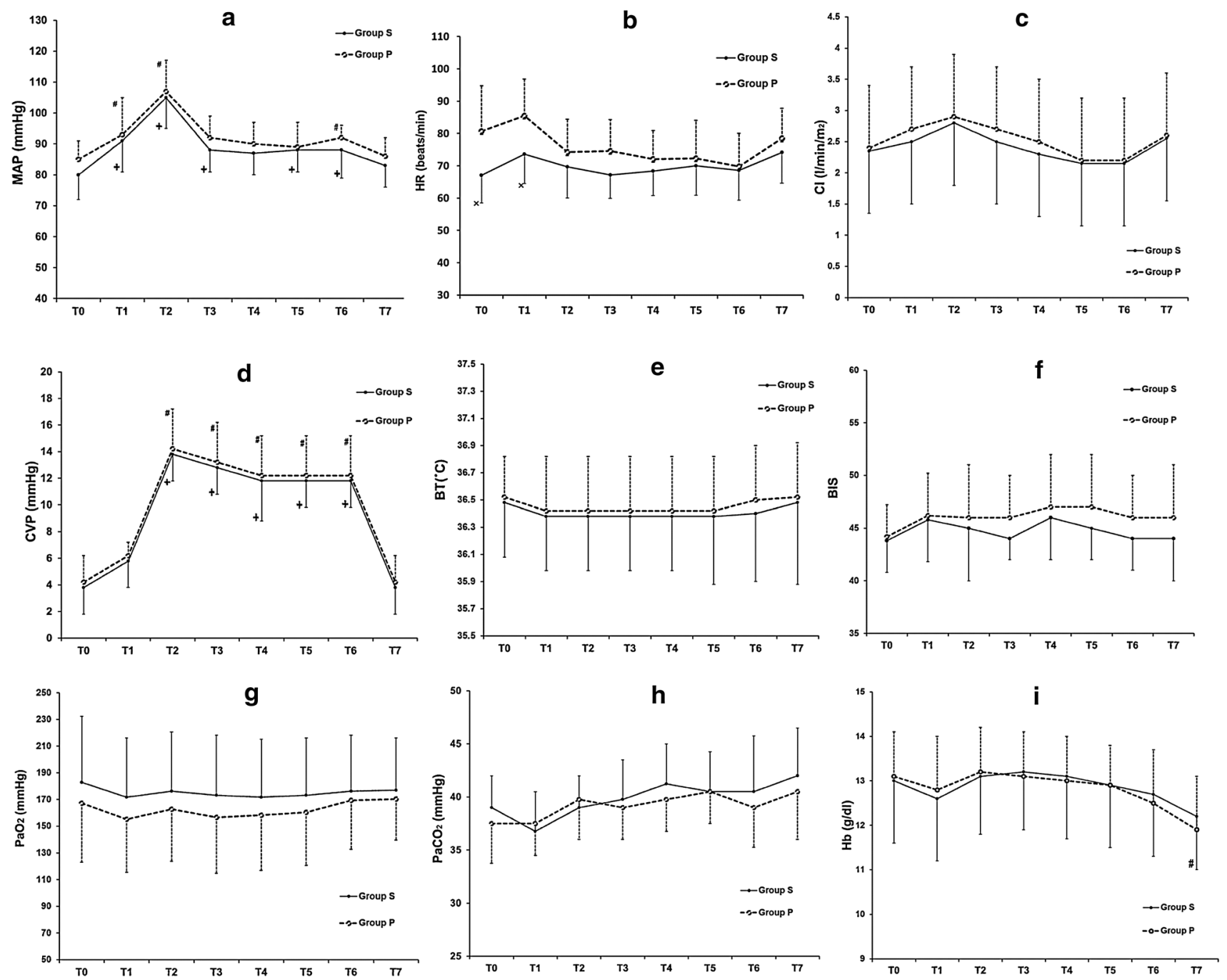

Fig. 3 Changes in a mean arterial pressure (MAP), b heart rate (HR), c cardiac index (CI), d central venous pressure (CVP), e nasopharyngeal temperature (BT), $\mathbf{f}$ Bispectral Index (BIS), $\mathbf{g}$ partial pressures of arterial oxygen $\left(\mathrm{PaO}_{2}\right)$, $\mathbf{h}$ partial pressures of carbon dioxide $\left(\mathrm{PaCO}_{2}\right)$, and $\mathbf{i}$ hemoglobin concentration $(\mathrm{Hb})$. Measurements were performed: $5 \mathrm{~min}$ before the commencement of surgery (T0); $5 \mathrm{~min}$

Figure 1 shows that the $\mathrm{SjO}_{2}$ was significantly higher in group $\mathrm{S}$ at all measurement points $(p<0.05)$ with no significant changes throughout the procedure when compared with T0. By contrast, Fig. 2 shows that there was no significant difference in the $\mathrm{SctO}_{2}$ values between the groups at each point, but that $\mathrm{SctO}_{2}$ was significantly higher at $\mathrm{T} 2$ than at $\mathrm{T} 0$ within each group.

Figure 3 shows that there were no differences across the measured time points between the groups in most of the key parameters that could affect $\mathrm{SjO}_{2}$ and $\mathrm{SctO}_{2}$. However, HR in group $\mathrm{S}$ was lower than that in group $\mathrm{P}$ at $\mathrm{T} 0$ and T1. Compared with T0, the MAP was significantly higher at T1-T6 in group S, and at T1, T2, and T6 in group P. In both groups, CVP was significantly higher during after a $15 \mathrm{mmHg}$ pneumoperitoneum (T1); 5, 30, 60, 90 and $120 \mathrm{~min}$ after the Trendelenburg position (T2, T3, T4, T5, and T6, respectively); and after exsufflation in the supine position (T7). Plus symbol $p<0.05$ vs. T0 in group S. Hash symbol $p<0.05$ vs. T0 in group P. Multi symbol $p<0.05$ vs. group $\mathrm{P}$

pneumoperitoneum in the Trendelenburg position (T2-T6) compared with $\mathrm{T} 0$. In group $\mathrm{P}, \mathrm{Hb}$ was significantly lower at $\mathrm{T} 7$ than at T0. Compared with T0, there were no differences within each group for $\mathrm{PaO}_{2}, \mathrm{PaCO}_{2}, \mathrm{CI}, \mathrm{Hb}$, BT, and BIS at each time point.

Figure 4 shows the linear regression analysis for $\mathrm{SjO}_{2}$ and $\mathrm{SctO}_{2}$ during anesthesia, with evidence of only a weak relationship $\left(\beta=0.106 ; r^{2}=0.065 ; p=0.004\right)$.

\section{Discussion}

The present study is the first to compare cerebral oxygenation by $\mathrm{SjO}_{2}$ between anesthetic regimens during RALP 


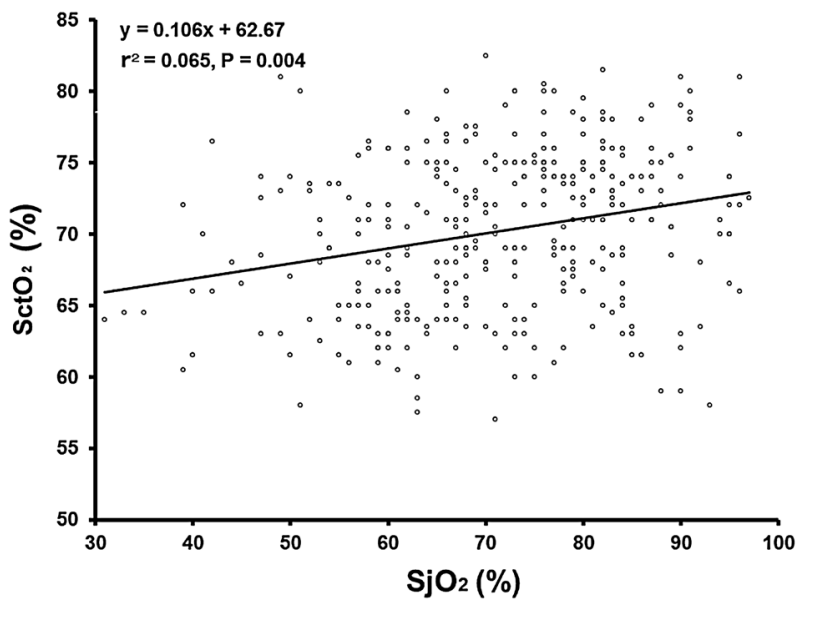

Fig. 4 Linear regression showing a weak relationship between regional oxygen saturation $\left(\mathrm{SctO}_{2}\right)$ and jugular venous oxygen saturation $\left(\mathrm{SjO}_{2}\right)$. Data are for 328 measurement pairs from 41 patients

and showed that sevoflurane had significantly higher levels of $\mathrm{SjO}_{2}$ than propofol at all measurement points. We also observed no intergroup differences in MAP, CI, CVP, BT, BIS, $\mathrm{PaO}_{2}, \mathrm{PaCO}_{2}, \mathrm{Hb}$ at any time point and in the total ephedrine and remifentanil dose, even though HR was lower in group $\mathrm{S}$ at $\mathrm{T} 0$ and $\mathrm{T} 1$. The difference in HR may be explained by the higher doses of ephedrine administered in group $\mathrm{P}$ to treat hypotension during this period. Although not statistically significant, the $\mathrm{PaO}_{2}$ of group $\mathrm{S}$ was higher by about $15 \mathrm{mmHg}$ at all measurement points, but this is likely too small to affect $\mathrm{SjO}_{2}$ physiologically and also from a literature review [14]. BT and BIS have been strongly related to cerebral metabolism $[15,16]$, but there were no significant differences in these values between the groups suggesting that there was no difference in $\mathrm{CMRO}_{2}$. Because we used sevoflurane at a mid-range concentration (above $1 \mathrm{MAC}$ ), we presumed that the cerebrovascular dilation effect was dominant in group $\mathrm{S}$ and that the intergroup differences in $\mathrm{SjO}_{2}$ were due to the differences in CBF.

Cerebral oxygen desaturation during surgery can predict early POCD and has been associated with delirium and prolonged hospitalization among the elderly [17, 18]. Current study might show that sevoflurane is better than propofol for RALP, but the result of our study does not directly indicate that sevoflurane is a superior choice for RALP. Cerebrovascular dilation effect of sevoflurane also implies the cerebrovascular dysregulation, which can be amplified during RALP [19] and could result in hyperemia and cerebral edema. These aspects must be clarified if we are to demonstrate the superiority of sevoflurane over propofol in a clinical setting because they might occur prior to a decrease in $\mathrm{SjO}_{2}$ or cerebral perfusion pressure. Although we performed no cognitive tests, our study might suggest the appropriateness of sevoflurane over propofol for patients with lower baseline values for
$\mathrm{SjO}_{2}$ due to cerebrovascular stenosis during pneumoperitoneum and a steep Trendelenburg position. A study comparing sevoflurane and propofol anesthesia among patients with baseline $\mathrm{SjO}_{2}$ values $<50 \%$ showed no differences in postoperative cognitive function [20], but the study did not show the $\mathrm{SjO}_{2}$ difference between the groups and did not control for $\mathrm{BP}, \mathrm{CI}$, or $\mathrm{PaCO}_{2}$, so we cannot assess the true relationship between the anesthetics, $\mathrm{SjO}_{2}$, and postoperative cognitive function. Several studies have shown the differences in cerebral oxygenation depending on the anesthetic used in a variety of clinical settings, but only a few have done so for pneumoperitoneum in the Trendelenburg position. One study tested whether $\mathrm{SctO}_{2}$ differed between propofol and sevoflurane anesthesia during laparoscopic surgery in a $20^{\circ}$ Trendelenburg position [21], and concluded that propofol was associated with significantly lower $\mathrm{SctO}_{2}$ than sevoflurane. In situations of raised ICP (e.g., brain tumors), research with volatile anesthetics have shown that they may maintain a significantly higher $\mathrm{SjO}_{2}$ compared with propofol [22]. Further, in the supine position for normal surgery [23], in the sitting position for arthroscopy [13], and during one-lung ventilation for lung surgery [24], volatile anesthetics can maintain higher cerebral oxygenation than propofol. One pilot study has reported that, compared with sevoflurane, propofol increased cerebral $\mathrm{SctO}_{2}$ only when the stimulus of surgery was intense [25]. Although the authors speculated that an increased propofol dose due to the stimulation caused the $\mathrm{CMRO}_{2}$ to decrease, the mechanism remains unclear because the concentrations of sevoflurane were not disclosed. Most of the studies discussed above, including the current study, indicate that volatile anesthetics cause higher cerebral oxygenation levels with no differences in neurological complications or POCD when compared with propofol anesthesia. We also showed that $\mathrm{SjO}_{2}$ was well preserved in both groups (>50 \%; Fig. 1). Although volatile anesthetics and propofol presumably have the potential to decrease cerebral oxygenation during RALP, we showed that neither did so. Considering the lack of significant changes in $\mathrm{SjO}_{2}$ compared with the baseline (T0), it is conceivable that pneumoperitoneum and a $30^{\circ}$ Trendelenburg position may not affect cerebral oxygenation within $2 \mathrm{~h}$. This may be because the predicted raise in ICP was within the physiological compensation, such as cerebrospinal fluid (CSF) and blood moving into the spinal canal and extracranial vasculature not to suppress cerebral oxygenation, and also may be due to the effect of cerebrovascular autoregulation although that might be partly impaired in group $S$.

We also found only a weak relationship between $\mathrm{SjO}_{2}$ and $\mathrm{SctO}_{2}$. There are several factors that could contribute to the inconsistency between the two values. First, $\mathrm{SjO}_{2}$ is an index of oxygenation for the entire brain, whereas $\mathrm{SctO}_{2}$ is an index of localized oxygenation in the frontal lobe [9-11, 26]. Second, NIRS measures blood oxygenation in arteries, 
veins, and capillaries combined; and is affected by extracerebral blood flow, cerebrospinal fluid, and systemic blood pressure. By contrast, $\mathrm{SjO}_{2}$ measures only the intracerebral mixed venous saturation [27, 28]. Interestingly, in this study, $\mathrm{SctO}_{2}$ showed similar changes to BP across time, whereas $\mathrm{SjO}_{2}$ did not. Third, NIRS calculates $\mathrm{SctO}_{2}$ based on a fixed artery-to-vein ratio, regardless of changes induced by the Trendelenburg position and anesthetic agents $[9,28]$.

The present study has several limitations. First, we did not routinely perform cognitive tests. Thus, it remains unclear whether postoperative cognitive outcomes correlate with differences in cerebral oxygenation by different anesthetic agents; further research is needed. Second, we measured $\mathrm{SjO}_{2}$ unilaterally, and although no research has shown a clear difference between left and right $\mathrm{SjO}_{2}$, this may have affected the results. Third, we did not include patients with cerebrovascular disease and complications, so we cannot state how the $\mathrm{SjO}_{2}$ or $\mathrm{SctO}_{2}$ would have responded to RALP in patients with a cerebral pathology. Fourth, the values for ICP, CBF, and $\mathrm{CMRO}_{2}$ were not measured directly, which should be rectified in future research. Fifth, we limited the time spent with a pneumoperitoneum in the Trendelenburg position to $120 \mathrm{~min}$, yet there have been reports of neurological complications due to brain edema when this procedure exceeds $8 \mathrm{~h}$ [29]. Actually, cerebrovascular autoregulation gradually changes with prolonged pneumoperitoneum in the Trendelenburg position; one study showed that it is decreased from 170 min [19]. Considering the inhibitory effect of volatile anesthetics on cerebrovascular autoregulation, it may be worth comparing the effects of longer surgery and steeper Trendelenburg positions in the future.

We conclude that sevoflurane allows for a higher $\mathrm{SjO}_{2}$ than propofol during RALP. We also conclude that $\mathrm{SctO}_{2}$ does not accurately reflect $\mathrm{SjO}_{2}$ during this procedure. Ultimately, further research is needed to determine the effect of anesthetics on hyperemia and cerebral edema during longer pneumoperitoneums and in steeper Trendelenburg positions, as well as on the potential correlation between postoperative cognitive outcomes and differences in cerebral oxygenation between anesthetic agents.

\section{Compliance with ethical standards}

Conflict of interest The authors declare no conflicts of interest associated with this manuscript.

Open Access This article is distributed under the terms of the Creative Commons Attribution 4.0 International License (http://creativecommons.org/licenses/by/4.0/), which permits unrestricted use, distribution, and reproduction in any medium, provided you give appropriate credit to the original author(s) and the source, provide a link to the Creative Commons license, and indicate if changes were made.

\section{References}

1. Mavrocordatos P, Bissonnette B, Ravussin P. Effects of neck position and head elevation on intracranial pressure in anesthetized neurosurgical patients. J Neurosurg Anesth. 2000;12:10-4.

2. Halverson A, Buchanan R, Jacobs L, Shayani V, Hunt T, Riedel C, Sackier J. Evaluation of mechanism of increased intracranial pressure with insufflation. Surg Endosc. 1998;12:266-9.

3. Dunham CM, Sosnowski C, Porter JM, Siegal J, Kohli C. Correlation of noninvasive cerebral oximetry with cerebral perfusion in the severe head injured patient: a pilot study. J Trauma. 2002;52:40-6.

4. Lee JR, Lee PB, Do SH, Jeon YT, Lee JM, Hwang JY, Han SH. The effect of gynaecological laparoscopic surgery on cerebral oxygenation. J Int Med Res. 2006;34:531-6.

5. Archer DP, Labrecque P, Tyler JL, Meyer E, Trop D. Cerebral blood volume is increased in dogs during administration of nitrous oxide or isoflurane. Anesthesiology. 1987;67:642-8.

6. Oshima T, Karasawa F, Satoh T. Effects of propofol on cerebral blood flow and the metabolic rate of oxygen in humans. Acta Anaesthesiol Scand. 2002;46:831-5.

7. Stephan H, Sonntag H, Schenk HD, Kohlhausen S. Effect of Disoprivan (propofol) on the circulation and oxygen consumption of the brain and $\mathrm{CO} 2$ reactivity of brain vessels in the human. Anaesthesist. 1987;36(2):60-5.

8. Monk TG, Weldon BC, Garvan CW, Dede DE, van der Aa MT, Heilman KM, Gravenstein JS. Predictors of cognitive dysfunction after major noncardiac surgery. Anesthesiology. 2008;108:18-30.

9. Liu J, Wang P, Zhang X, Zhang W, Gu G. Effects of different concentration and duration time of isoflurane on acute and longterm neurocognitive function of young adult C57BL/6 mouse. Int J Clin Exp Pathol. 2014;7:5828-36.

10. Ballard C, Jones E, Gauge N, Aarsland D, Nilsen OB, Saxby BK, Lowery D, Corbett A, Wesnes K, Katsaiti E, Arden J, Amoako D, Prophet N, Purushothaman B, Green D. Optimised anaesthesia to reduce post-operative cognitive decline (POCD) in older patients undergoing elective surgery, a randomised controlled trial. PLoS One. 2012;7:e37410.

11. Schell RM, Cole DJ. Cerebral monitoring: jugular venous oximetry. Anesth Anal. 2000;90:559-66.

12. Casati A, Spreafico E, Putzu M, Fanelli G. New technology for noninvasive brain monitoring: continuous cerebral oximetry. Minerva Anesthesiol. 2006;72:605-25.

13. Jeong H, Jeong S, Lim HJ, Lee JU, Yoo KY. Cerebral oxygen saturation measured by Near-infrared spectroscopy and jugular venous bulb oxygen saturation during arthroscopic shoulder surgery in beach chair position under sevoflurane-nitrous oxide or propofol-remifentanil anesthesia. Anesthesiology. 2012;116:1047-56.

14. Legrand M, Vallée F, Mateo J, Payen D. Influence of arterial dissolved oxygen level on venous oxygen saturation: don't forget the PaO2! Shock. 2014;41:510-3.

15. Michenfelder JD. Anesthesia and brain: clinical, functional, metabolic, and vascular correlates. New York: Churchill Livingstone; 1988.

16. Alkire MT. Quantitative EEG correlations with brain glucose metabolic rate during anesthesia in volunteers. Anesthesiology. 1998;89:323-33.

17. Tang L, Kazan R, Taddei R, Zaouter C, Cyr S, Hemmerling TM. Reduced cerebral oxygen saturation during thoracic surgery predicts early postoperative cognitive dysfunction. Br J Anaesth. 2012;108:623-9.

18. Kadoi Y, Saito S, Goto F, Fujita N. Decrease in jugular venous oxygen saturation during normothermic cardiopulmonary bypass 
predicts short-term postoperative neurologic dysfunction in elderly patients. J Am Coll Cardiol. 2001;38:1450-5.

19. Schramm P, Treiber AH, Berres M, Pestel G, Engelhard K, Werner C, Closhen D. Time course of cerebrovascular autoregulation during extreme Trendelenburg position for robotic-assisted prostatic surgery. Anaesthesia. 2014;69:58-63.

20. Guo JY, Fang JY, Xu SR, Wei M, Huang WQ. Effects of propofol versus sevoflurane on cerebral oxygenation and cognitive outcome in patients with impaired cerebral oxygenation. Ther Clin Risk Manag. 2016;12:81-5.

21. Kim SJ, Kwon JY, Cho AR, Kim HK, Kim TK. The effects of sevoflurane and propofol anesthesia on cerebral oxygenation in gynecological laparoscopic surgery. Korean J Anesth. 2011;61:225-32.

22. Muñoz HR, Núñez GE, de la Fuente JE, Campos MG. The effect of nitrous oxide on jugular bulb oxygen saturation during remifentanil plus target controlled infusion propofol or sevoflurane in patients with brain tumors. Anesth Anal. 2002;94:389-92.

23. Valencia L, Rodríguez-Pérez A, Kühlmorgen B, Santana RY. Does sevoflurane preserve regional cerebral oxygen saturation measured by near-infrared spectroscopy better than propofol? Ann Fr Anesth Reanim. 2014;33:e59-65.

24. Iwata M, Inoue S, Kawaguchi M, Takahama M, Tojo T, Taniguchi S, Furuya H. Jugular bulb venous oxygen saturation during one-lung ventilation under sevoflurane- or propofolbased anesthesia for lung surgery. J Cardiothorac Vasc Anesth. 2008;22:71-6.

25. Sen P, Izdes S, But A. Effects of sevoflurane and propofol anaesthesia on cerebral oxygenation during normocapnia and mild hypercapnia: a pilot study. Br J Anaesth. 2013;110:318-9.

26. Yoshitani K, Kawaguchi M, Iwata M, Sasaoka N, Inoue S, Kurumatani N, Furuya H. Comparison of changes in jugular venous bulb oxygen saturation and cerebral oxygen saturation during variations of haemoglobin concentration under propofol and sevoflurane anaesthesia. Br J Anaesth. 2005;94:341-6.

27. Yoshitani K, Kawaguchi M, Miura N, Okuno T, Kanoda T, Ohnishi Y, Kuro M. Effects of hemoglobin concentration, skull thickness, and the area of the cerebrospinal fluid layer on near-infrared spectroscopy measurements. Anesthesiology. 2007;106:458-62.

28. Pollard V, Prough DS, DeMelo AE, Deyo DJ, Uchida T, Widman $\mathrm{R}$. The influence of carbon dioxide and body position on nearinfrared spectroscopic assessment of cerebral hemoglobin oxygen saturation. Anesth Anal. 1996;82:278-87.

29. Pandey R, Garg R, Darlong V, Punj J, Chandralekha, Kmar A. Unpredicted neurological complications after robotic laparoscopic radical cystectomy and ileal conduit formation in steep Trendelenburg position: two case reports. Acta Anaesthesiol Belg. 2010;61:163-6. 